\title{
Triple Effect of Doxorubicin, 5-Fluorouracil, Propranolol on Cell Survival on MCF-7 Breast Cancer Cell Line
}

\author{
Onur Eroglu1,2*, Hacer Kaya' ${ }^{1}$, Esin Guvenir Celik ${ }^{1}$, Merve Celen ${ }^{3}$, Elif Korkut ${ }^{4}$, Nagihan Nizam ${ }^{1}$ \\ ${ }^{1}$ Department of Molecular Biology and Genetics, Faculty of Science and Letters, Bilecik Seyh Edebali University, Bilecik, Turkey \\ ${ }^{2}$ Biotechnology Research and Application Center, Bilecik Seyh Edebali University, Bilecik, Turkey \\ ${ }^{3}$ Vocational School of Medical Services, Program of Medical Laboratory Techniques, Bilecik Seyh Edebali University, Bilecik, \\ Turkey \\ ${ }^{4}$ Department of Medical Genetics, Faculty of Medicine, Başkent University, Ankara, Turkey \\ Email: *onur.eroglu@bilecik.edu.tr
}

How to cite this paper: Eroglu, O., Kaya, H., Celik, E.G., Celen, M., Korkut, E. and Nizam, N. (2019) Triple Effect of Doxorubicin, 5-Fluorouracil, Propranolol on Cell Survival on MCF-7 Breast Cancer Cell Line. Journal of Biosciences and Medicines, 7 , 74-85.

https://doi.org/10.4236/jbm.2019.72007

Received: January 4, 2019

Accepted: February 11, 2019

Published: February 14, 2019

Copyright () 2019 by author(s) and Scientific Research Publishing Inc. This work is licensed under the Creative Commons Attribution International License (CC BY 4.0).

http://creativecommons.org/licenses/by/4.0/

\section{(c) (i) Open Access}

\begin{abstract}
Purpose: Investigating the triple effect of doxorubicin, 5-fluorouracil, propranolol on MCF-7 (ER+, WTp53) breast cancer cell line with MTT test and survival analysis. Materials/Methods: In order to determine effective dosages of a combination of doxorubicin, 5-fluorouracil, propranolol on the MCF-7 cell line by using MTT and survival analysis technique. Result: $\mathrm{IC}_{50}$ values acquired by MTT tests are $0.01 \mathrm{mg} / \mathrm{ml}$ for doxorubicin, $6 \mathrm{mg} / \mathrm{ml}$ for 5-fluorouracil, $30 \mathrm{mg} / \mathrm{ml}$ for propranolol and $0.2 / 1 / 30 \mathrm{mg} / \mathrm{ml}$ (with previous respect) if all three agents are combined. It is found that the use of doxorubicin, 5-fluorouracil, and propranolol in combination is much effective than their single application. Discussion: Moderate concentrations of doxorubicin, 5-fluorouracil, and propranolol, if they are applied individually, showed high toxicity. When we used these drugs in combination; toxic effects lessened with respect to monotherapy. In the MCF-7 cell line, doxorubicin $\left(\mathrm{IC}_{50}\right.$ : $0.01 \mu \mathrm{M})$ increases cell death rates significantly and propranolol $\left(\mathrm{IC}_{50}: 3 \mu \mathrm{M}\right)$ has minimum effects in monotherapy in contrast to others. Propranolol is only superior to itself in combination therapy $\left(\mathrm{IC}_{50}: 4 \mu \mathrm{M}\right)$. However 5-fluorouracil $\left(\mathrm{IC}_{50}: 30 \mu \mathrm{M}\right)$ showed antagonistic effects with respect to other drugs. Additionally, having applied the three drugs in combination on the MCF-7 cell line for the first time in literature, it is highly possible to assess the application of doxorubicin, 5-fluorouracil and propranolol combination as a novel therapy option.
\end{abstract}

\section{Keywords}

MCF-7, Breast Cancer, Combine Treatment, Doxorubicin, 5-Fluorouracil, Propranolol 


\section{Introduction}

Breast cancer is the most frequent cancer seen in women with an increasing incidence. In order to succeed in cancer therapy, usually, more than one chemotherapeutic agent is applied. Under current economic and financial circumstances, utilizing currently approved medicine for new indications to reposition them is an increasingly popular strategy. It is aimed to abate important risks and alleviate financial issues with the aid of well-known toxicity and pharmacogenetics of these agents [1] [2].

Resistance against present therapies is often a concurrently increasing problem with treatment. To succeed in cancer therapy, usually more than a single chemotherapeutic agent is required. However, antecedent or preexisting drug resistance is the most significant obstacle to succeed in cancer chemotherapy. This condition is named Multiple Drug Resistance (MDR) [3]. Having comprehended molecular mechanisms behind multiple drug resistance, further therapies can be discovered.

Breast Cancer Cell Lines are widely exercised for breast cancer modeling. Cell lines provide unlimited homogenous material for tumor studies and, moreover, since they are able to produce relatively easy cultures, breast cancer cell lines are obtained in vivo and in vitro for studies [4].

Anthracyclines are Cell Cycle Non-Specific agents (CCNS) [5] which are applied in cancer therapy, a drug class isolated from Streptomyces peucetius Caesius, a species of actinobacteria [6]. Discovery of anthracyclines retained their popularity among scientific and clinical research sites due to their anti-tumor effects and their effects on cardiotoxic mechanisms. Anthracyclines are used in leukemia, lymphoma, breast cancer, stomach cancer, ovarian cancer and, lung cancer therapy [7]. Doxorubicin, daunorubicin, epirubicin, idarubicin, and mitoxantrone are some examples of chemotherapeutic agents of anthracycline family.

Doxorubicin (dox), which belongs to anthracycline family, is one of the most widely used drugs in breast cancer therapy also an agent to treat ovarian, lung, urinary, bladder, thyroid and stomach cancers as well as lymphoma [8] [9]. Doxorubicin inhibits DNA synthesis by intercalating DNA helix [10]. This inhibition is executed by preventing the advance of enzyme topoisomerase II along DNA molecule [11] [12]. During replication, having stabilized topoisomerase, DNA double-helix structure becomes unable to be resealed and the cell undergoes apoptosis [13] [14].

Fluorouracil (5-FU) is one of the ubiquitous chemotherapy drugs. It is applied frequently to tumors of solid tissues found in breast, colon, rectum, pancreas, and stomach cancers [15]. 5-fluorouracil is an analog of uracil which contains fluorine instead of hydrogen at position C5. It is converted intra-cellularly into many metabolites: fluorodeoxyuridine monophosphate (FdUMP), fluorodeoxyuridine triphosphate (FdUTP), fluorouridine triphosphate (FUTP). These active metabolites vitiate RNA synthesis and thymidylate synthase enzyme activity 
[16]. Thymidylate Synthase (TS) enzyme catalyzes the conversion of deoxythymidine monophosphate (dTMP) into deoxyuridine monophosphate (dUMP). An active metabolite of 5-FU fluorodeoxyuridine monophosphate (FdUMP) bonds to nucleotide binding site of thymidylate synthase and forms a stable structure. Access to nucleotide binding site of dUMP is prevented and dTMP synthesis is inhibited. This event results in instability of nucleotide pool and increases in deoxyuridine triphosphate level. Both events cause DNA damage. The level of DNA damage resulted from dUTP depends on the levels of pyrophosphatase, dUTPase, and uracil-DNA-glycosylase (UDG) [17]. dTMP can be acquired from thymidine with the help of Thymidine-Kinase (TK). This acquisition way represents a potential resistance mechanism of 5-FU. Drug metabolism and activity of Dihydropyrimidine-Dehydrogenase (DPD), which plays an essential role in deactivation of fluorouracil, are reduced due to a genetic variation seen among $3 \%-8 \%$ of patients. Intense toxic reactions seen on the patients with that genetic variation might be fatal even on low dose applications of fluorouracil.

Propranolol (prop) is classified as a beta-blocker, non-selective and generally used in hypertension and arrhythmia. It blocks epinephrine and norepinephrine action on adrenergic $\beta_{1}$ and $\beta_{2}$ receptors. It shows very little sympathomimetic activity although it has strong membrane stabilizing activity. Its enantiomers exhibit local anesthetic effect which is usually accomplished by blocking voltage-gated sodium channels [17]. Propranolol shows its effect on cell proliferation via cell cycle components cyclin-E and CDK2 [18]. Several studies evince propranolol's ability to block voltage-gated sodium channels of cardiac, neural and skeleton cells and its membrane stabilizing, anti-arrhythmic effects and other effects on the central nervous system should be of concern [19]. In this study, the triple effect of doxorubicin, 5-fluorouracil, and propranolol combined applied on MCF-7 cells in order to reduce toxicities of these drugs on cells in contrast to their monotherapy. In the future, triple combination doxorubicin, fluorouracil, and propranolol might be considered as a novel therapy.

\section{Materials and Methods}

\subsection{Cell Line}

One of the cell lines used in breast cancer MCF-7 (ER (+), WTp53) were luminal epithelial tissue cells originated from metastatic pleural effusion obtained from a white, 69 years old, female patient with primary carcinomatous ductal tumor. MCF-7 breast cancer cell lines are provided by Prof. Oğuz Öztürk, DETAE (Experimental Medicine Research Institute).

\subsection{Cell Culture}

The main constituent of media for cell culture was RPMI however 10\% FBS and $0.1 \%$ penicillin-streptomycin was applied to prevent microbial infections. Cell line cultures were cultivated in a sterile incubator under the conditions of $5 \%$ 
$\mathrm{CO}_{2}$ and $37^{\circ} \mathrm{C}$ (Memmert $\mathrm{CO}_{2}$ Incubator, INCO153med, Germany). Growing cells were re-passaged when they cover up to $80 \%$ of the volume of the container flask.

\subsection{Cell Vitality Test (MTT Test)}

3-(4,5-dimethylthiazol-2-yl)-2,5-diphenyltetrazolium bromide or MTT assay test was applied to incubated breast cancer cell line in order to assess time-dependent dosage effects of Dox, 5-FU and Prop. The percentage of inhibition results $\left(\mathrm{IC}_{50}\right)$ were calculated by using the formula $Y=m x+C(Y=$ Inhibition, $x=$ Concentration, $C=$ Constant, $m=$ Coefficient). Cells are treated with $0.001-3 \mu \mathrm{M}$ Dox, $0.01 \mu \mathrm{M} 5$-FU, 1 - $250 \mu \mathrm{M}$ Prop for a period of 24 hours. Readings of spectrophotometry at a wavelength of $570 \mathrm{~nm}$ were analyzed so as to determine relative cell survival rates of the control group versus drug applied cell group. (Mul$\operatorname{tiskan}^{\mathrm{rm}}$ FC Microplate Photometer, ThermoFisher Scientific, Multiskan FC China).

\subsection{Survival/Trypan Blue Test}

To assess cytotoxic effects of applied drugs trypan blue is used to experiment cell survival rates. MCF-7 cell line control and Dox, 5-FU, Prop triple combination application groups were designated to include $1 \times 10^{5}$ cells in each well and implanted onto Petri dishes with 6 wells. Cells were treated with drugs for periods of 24, 48 and 72 hours according to the determined $\mathrm{IC}_{50}$ values set as per MTT results. Then, Trypan Blue was applied and their numbers were counted with Neubauer hemocytometer.

\subsection{Statistical Analysis}

The results were obtained by taking the average of three experimental replicates and data were analyzed with the Graph Pad 4.04 statistics software. The independent $\mathrm{t}$-test was used for the comparisons and $\mathrm{p}$-value $<0.05$ was determined for significant changes.

\section{Results}

\subsection{MTT Results}

$\mathrm{IC}_{50}$ values obtained from MTT results are determined as $0.01 \mathrm{mg} / \mathrm{ml}$ for doxorubicin, $6 \mathrm{mg} / \mathrm{ml}$ for 5-fluorouracil, $30 \mathrm{mg} / \mathrm{ml}$ for propranolol and for the triple combination, the dose range of $0.2 / 1 / 30 \mathrm{mg} / \mathrm{ml}$ was selected which was effective at a low dose of doxorubicin/5-fluorouracil/propranolol (Figure 1). Acquired ELISA results are demonstrated as column charts in Microsoft Office Excel and standard deviations are calculated and shown for each graph. Each chart is plotted according to data on relative cell survival ratio to control group and each experiment was designated to repeat thrice (Figures 2-4) $(\mathrm{p}<0.05)$.

\subsection{Survival Results}

Survival analysis of breast cancer cells, which were treated with doxorubicin, 
5-fluorouracil, propranolol alone and in triple combination for periods of 24 and 48 hours according to the determined $\mathrm{IC}_{50}$ values set as per MTT results, is demonstrated in Figure 5 \& Figure $6(\mathrm{p}<0.05)$.

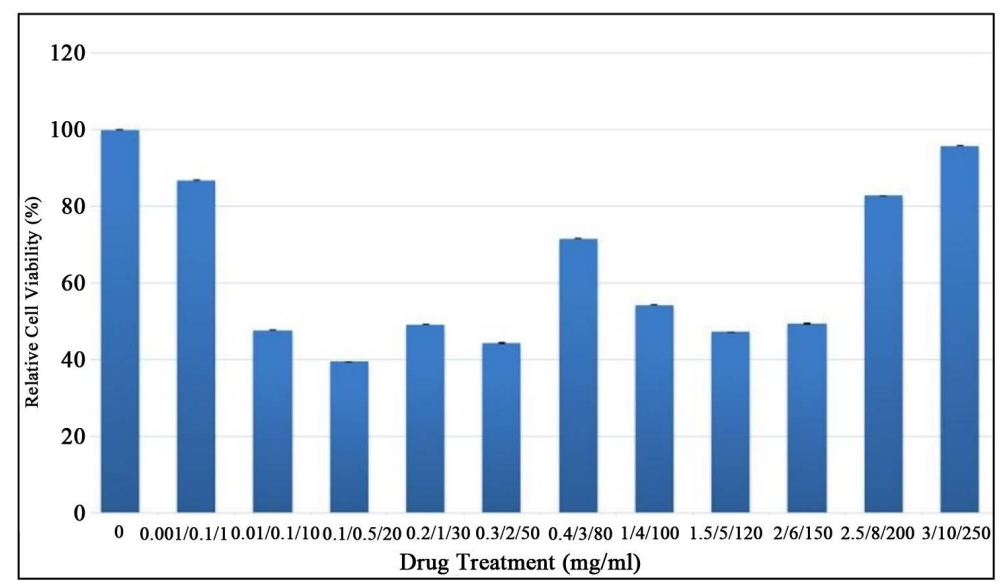

Figure 1. MTT results for combination therapy of doxorubicin, 5-fluorouracil and, propranolol.

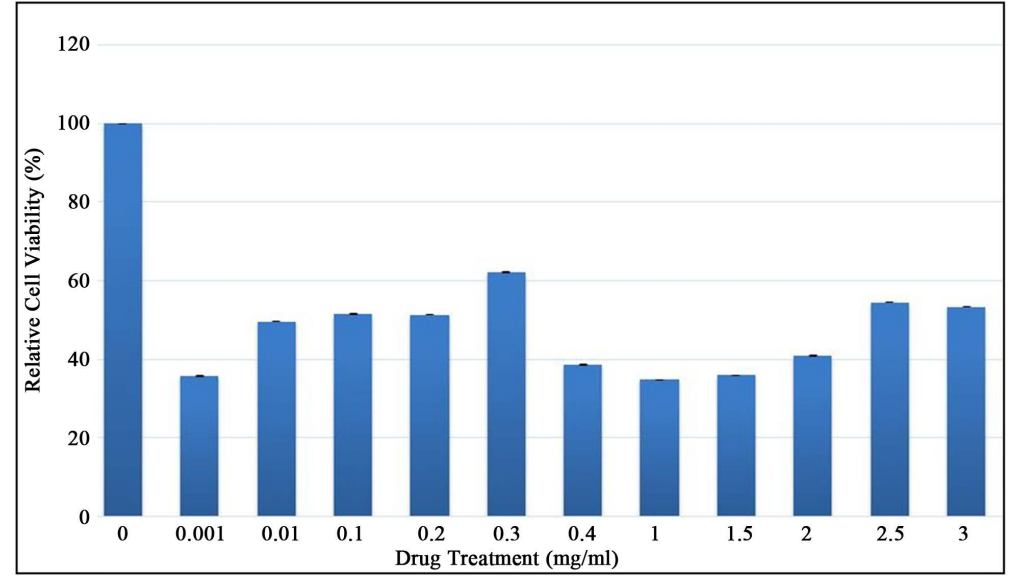

Figure 2. MTT results for doxorubicin ( $\left.\mathrm{IC}_{50}: 0.01 \mathrm{mg} / \mathrm{ml}\right)$.

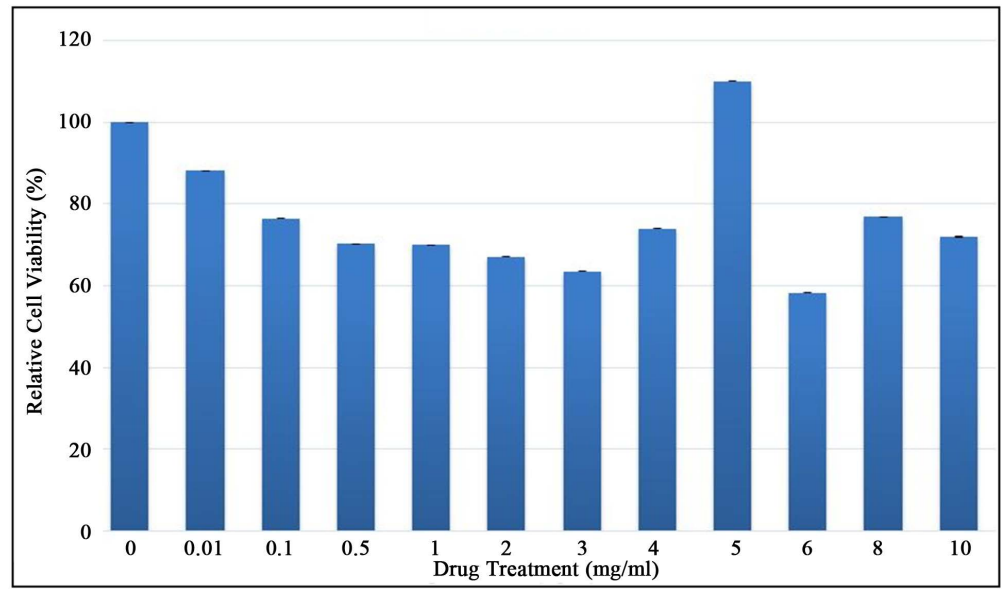

Figure 3. MTT results for 5-fluorouracil $\left(\mathrm{IC}_{50}: 6 \mathrm{mg} / \mathrm{ml}\right)$. 


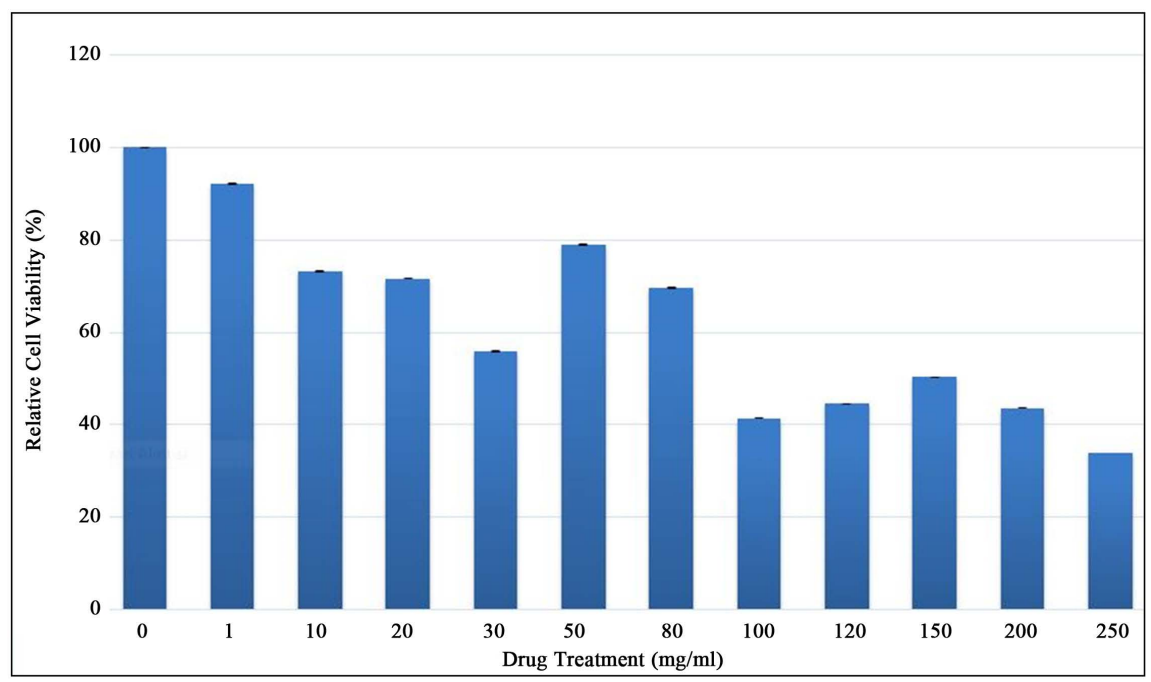

Figure 4. MTT results for propranolol (IC $\mathrm{IC}_{50}: 30 \mathrm{mg} / \mathrm{ml}$ ).

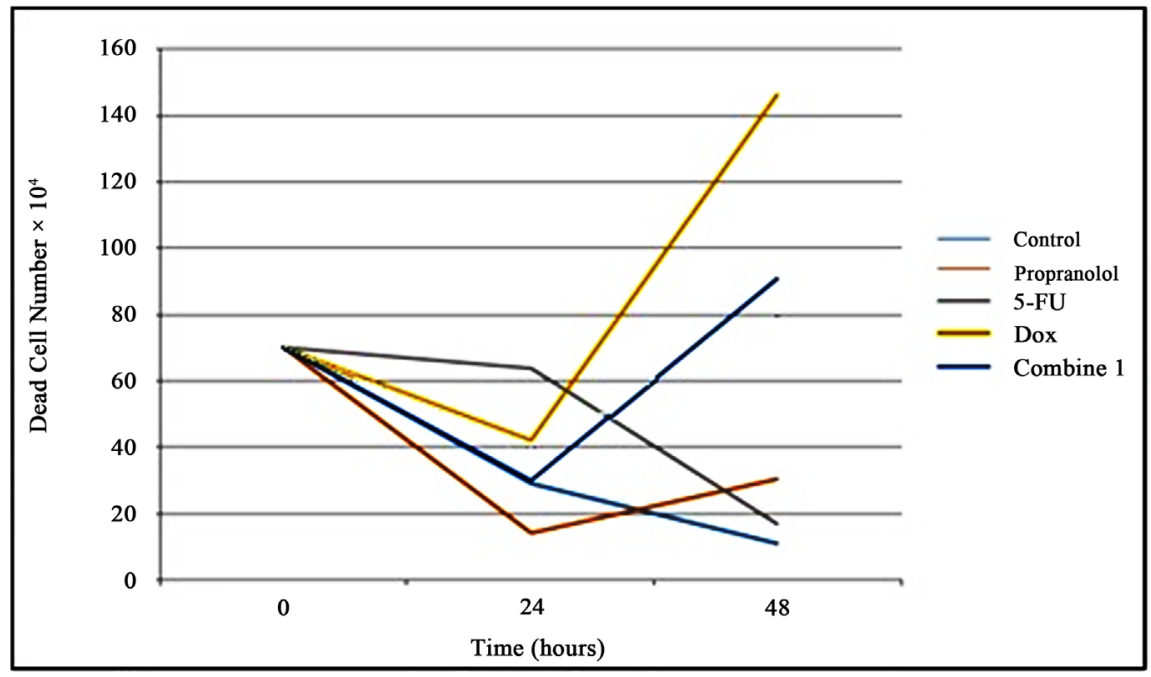

Figure 5. Time-dependent dead cell number graph.

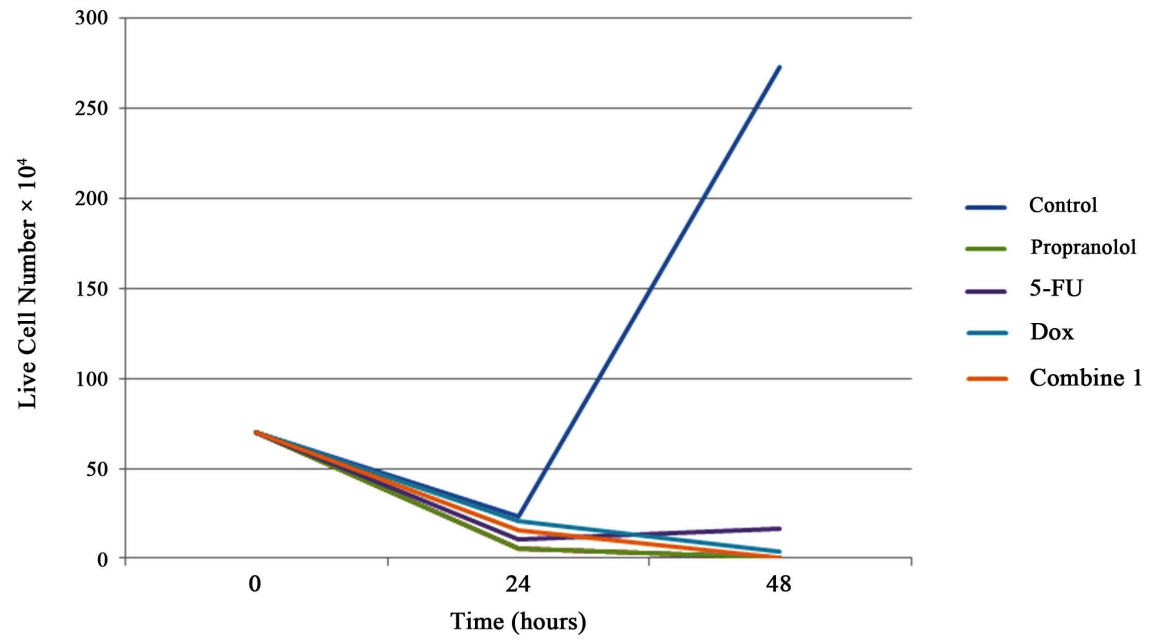

Figure 6. Time-dependent live cell number graph. 


\section{Discussion}

Nowadays, it is well understood that treating cancer with a single drug or single therapy does not suffice. In many studies, it is intended that numerous drugs and supplementary therapy procedures (surgical, radiotherapy, hyper-thermal regional ablative therapies and minimally invasive surgeries) are applied in combination in order to designate a more effectual therapy for the patient and minimize adverse effects. Monotherapy is not effectual in healing the disease and various therapy types are required to apply in sequence and sometimes concurrently.

It is reported that some drugs that might create systemic toxicity are not applied under effectual dosage to affect cancerous tissue. A major limitation for the use of doxorubicin is its cardiotoxicity. Researchers aimed to reduce the toxicity of anthracycline drugs [20]. 5-FU is catabolized by dihydropyrimidine dehydrogenase (DPD), which is encoded by the dihydropyrimidine gene and plays an important role [21]. DPD is the initial rate-limiting enzyme in the catabolic pathway of 5-FU [22]. Hence any alteration in this sequence of enzymatic activity can lead to toxic accumulation of 5-FU [21]. The reduced activity of the enzyme increases the half-life of the drug, resulting in excess accumulation of the drug and subsequent toxicity [23]. Cancer patients with a complete or near complete deficiency of the DPD enzyme suffered from severe toxicity, which may even cause death after treatment of 5-fluorouracil [24] [25]. Propranolol is associated with heart failure, heart block, hypotension, worsening of symptoms in psoriasis, asthma, and psychosis [26]. Therefore, incorporating combination therapies are found plausible [27].

In our study, the toxicity of doxorubicin is found to be much higher than 5-fluorouracil and propranolol. In monotherapy, on MCF-7 cell line doxorubicin $\left(\mathrm{IC}_{50}: 0.01 \mu \mathrm{M}\right.$ ) increases cell death rates significantly (Figure 2); propranolol $\left(\mathrm{IC}_{50}: 30 \mu \mathrm{M}\right)$ has minimum effects in monotherapy among others (Figure 4). When the triple is applied, the number of dead cells increases as like Dox monotherapy despite a lower rate (Figure 5). Although the single dose of Dox is doing much better than the combination of three agents, we decide to use the combination of three to reduce the side effects of Dox. Additionally, having applied for the first time in literature, we think that it seems highly possible to assess the application of doxorubicin, 5-fluorouracil and propranolol combination as a novel therapy option.

Zoli et al. (2005) applied triple chemotherapeutic agents in a sequence as doxorubicin $\rightarrow$ paclitaxel $\rightarrow 48$ hours $\rightarrow$ washing $\rightarrow 5$-fluorouracil in accordance with clinic phase I/II protocols. In these studies, doxorubicin, paclitaxel, and 5-fluorouracil were applied in a ratio as 1:1:10 and in addition to doxorubicin and paclitaxel 5-fluorouracil was also added to study their effects on human breast cancer cell lines MCF-7 and BRC-230. In contrast to our study, Zoli et al. applied the triple chemotherapeutic combination in a sequence as per doxorubicin $\rightarrow$ paclitaxel $\rightarrow 48$ hours $\rightarrow$ washing $\rightarrow 5$-fluorouracil in accordance with clinic 
phase I/II protocols. In these studies, doxorubicin, paclitaxel, and 5-fluorouracil were applied in a ratio as 1:1:10. Moreover, here, it is possible to determine a protocol to employ these three chemical agents by defining their combinatory use and synergetic and antagonist effects. Furthermore, specifically dox $\rightarrow$ parcel sequence blocks the cells on G2-M and when 5-FU added, it was revealed that cells are suppressed to advance in a cell cycle and resulted in the death of cells. Dox $\rightarrow$ Pacl pre-application caused an obvious decrease in basal TS expression and probably promoted 5-FU activity. Doxorubicin $\rightarrow$ paclitaxel $\rightarrow 48$ hours $\rightarrow$ washing $\rightarrow 5$-fluorouracil sequence resulted in induction of apoptosis with no regard to hormonal, p53, bcl-2 or p53 in both experiments. In multiple chemotherapy application protocols, for optimized drug activity, it is claimed that the drug application sequence and dosage are the most important steps [28].

As said by Kugawa et al. (2004) CPA, dox and 5-FU induces apoptosis in MCF-7 cells. Dosage dependence of single anti-cancer drugs was determined as per cited data and after anti-cancer drug application vitality of MCF-7 cells were equally reduced. Even used at minimal concentration dox is reported to have the highest toxicity among the three. In addition, having treated MCF-7 cells with monotherapy for four days, an induced cell death rate of $60 \%$ was reached by 5 $\mu \mathrm{g} / \mathrm{ml}$ and $25 \mu \mathrm{g} / \mathrm{ml}$ for dox and 5-FU respectively. When treated with the triple combination, $60 \%$ cell death rate was reached in two or three days. According to biochemical analysis, in dox monotherapy and triple combination, DNA fragmentation was observed while others didn't show the same. It is emphasized that death of human breast cancer cell line MCF-7 induced by anti-cancer drugs might or might not be apoptotic however if a combination is applied it would be entirely apoptotic [29].

Pasquier et al. (2006) showed that by using propranolol at low concentrations in 9 different types of cell lines including MCF-7, anti-proliferative effects of chemotherapeutic drugs can be modulated in vitro, cell-specifically and dose-dependently. Human breast carcinoma and vesicular endothelial cell lines are among most sensitives to propranolol and chemotherapy. If low dose propranolol is combined with 5-fluorouracil and paclitaxel, propranolol increases in vitro angiogenesis inhibition significantly and by affecting endothelial cells directly since it boosts anti-angiogenetic features of chemotherapeutic drugs. Although differences do not indicate statistical significance, it is found that propranolol exhibits higher anti-tumor tendencies when combined with chemotherapy in contrast to chemotherapy alone [30].

Boosting in vitro antiproliferative and anti-angiogenetic effects of chemotherapeutic drugs were proven to be boosted by two potential mechanisms of propranolol's in vivo anti-tumor features. Previous studies exhibited propranolol's effect on pre-clinic models of both ovarian and breast cancers which are induced by stress to inhibit metastasis however it can only affect the growth of primary tumor of ovarian cancer model [31] [32] [33].

In our study, it is observed that concentrations of the drugs show high toxicity due to higher concentrations in monotherapy although when applied in combi- 
nation, toxic effects lessened with respect to monotherapy. In designing protocols of clinical applications which include multiple chemotherapeutic agents, effects of different agents and their cytotoxic effects and synergetic effects of agents, when applied in combination, should be taken in consideration [34] [35] [36]. Optimization of protocols of multiple chemotherapeutic agent application is regarded as the most vital step of the therapy phase and dosage [37].

Considering future clinical trials, evaluation of such combination therapy is a necessity especially for patients who are prone to develop drug resistance with regard to an effective treatment strategy. If succeeded, it will be possible to treat more than a million women with breast cancer in an economic way in a short period. In order to investigate the synergetic and antagonist effects of these drugs with each other, a future study of double combinations of the drugs is already proposed. By the aid of these proposed results, effectual treatments might be possible with a lower dose and minimal cytotoxic effects on the patient. Since cancer generating mechanisms are not solved thoroughly, developing drugs which target these mechanisms is restricted. Moreover, current and future drug resistance is another obstacle against drug development. Usually, more than one chemotherapeutic agent is applied to succeed in cancer treatment.

In this study, having determined cytotoxic effects of doxorubicin, 5-fluorouracil and propranolol concentrations, it became evident that the agents should be tried in more frequent intervals, this study should be described as a first step and more sophisticated studies might be proposed. Meanwhile, more detailed molecular, in vitro and in vivo studies which can reveal the actual potential of the triple combination are also required. Finally, cytotoxic effects of doxorubicin, 5-fluorouracil and propranolol were minimized and their concurrent use is proposed to be a suitable combination therapy.

\section{Acknowledgements}

This study was done at Biotechnology Research and Application Center and Molecular Biology and Genetics Department in Bilecik Seyh Edebali University, Bilecik, Turkey in 2016.

\section{Conflicts of Interest}

The authors declare that they have no competing interests.

\section{References}

[1] Amstutz, U., Froehlich, T.K. and Largiadèr, C. (2011) Dihydropyrimidine Dehydrogenase Gene as a Major Predictor of Severe 5-Fluorouracil Toxicity. Pharmacogenomic, 12, 1321-1336.

[2] Eroglu, O. (2018) Investigation of Cytotoxic and Anti-Proliferative Effects of Betamethasone Valerate (BMV) on MDA-MB 231 Breast Cancer Cell Line. GMJ, 29, 331-335. https://doi.org/10.12996/gmj.2018.89

[3] Ueda, K., Cardarelli, C., Gottesman, M.M. and Pastan, I. (1987) Expression of a Full-Length cDNA for the Human "MDR1" Gene Confers Resistance to Colchicine, 
Doxorubicin, and Vinblastine. Proceedings of National Academy of Sciences of USA, 84, 3004-3008. https://doi.org/10.1073/pnas.84.9.3004

[4] Dai, X., Cheng, H., Bai, Z. and Jia, Li. (2017) Breast Cancer Cell Line Classification and Its Relevance with Breast Tumor Subtyping. Journal of Cancer, 8, 3131-3141. https://doi.org/10.7150/jca.18457

[5] Trevor, A., Katzung, B. and Masters, S. (2012) Pharmacology: Examination and Board Review, Anthracycilne Antibiotics. McGraw Hill Medical Books, Pennsylvania Plaza New York City.

[6] Fujiwara, A., Hoshino, T. and Westley, J. (1985) Anthracycline Antibiotics. Critical Reviews in Biotechnology, 3, 133-137. https://doi.org/10.3109/07388558509150782

[7] McGowan, J.V., et al. (2017) Anthracycline Chemotherapy and Cardiotoxicity. Cardiovascular Drugs and Therapy, 31, 63-75.

[8] Arcamone, F., Cassinelli, G., Fantini, G., Grein, A., Orezzi, P., Pol, C. and Spalla, C. (1969) Adriamycin, 14-Hydroxydaunomycin, a New Antitumor Antibiotic from $S$. Peucetius var. caesius. Biotechnology and Bioengineering, 11, 1101-1110. https://doi.org/10.1002/bit.260110607

[9] Malla, S., Niraula, N.P., Singh, B., Liou, K. and Sohng, J.K. (2010) Limitations in Doksorubisin Production from Streptomyces peucetius. Microbiological Research, 165, 427-435. https://doi.org/10.1016/j.micres.2009.11.006

[10] Tacar, O., Sriamornsak, P. and Dass, C.R. (2013) Doxorubicin: An Update on Anticancer Molecular Action, Toxicity and Novel Drug Delivery Systems. The Journal of Pharmacy and Pharmacology, 65, 157-170. https://doi.org/10.1111/j.2042-7158.2012.01567.x

[11] Pang, B., Qiao, X., Janssen, L., Velds, A., Groothuis, T., Kerkhoven, R., Nieuwland, M., Ovaa, H., Rottenberg, S., Van Tellingen, O., Janssen, J., Huijgens, P., Zwart, W. and Neefjes, J. (2013) Drug-Induced Histone Eviction from Open Chromatin Contributes to the Chemotherapeutic Effects of Doxorubicin. Nature Communications, 4, Article Number: 1908. https://doi.org/10.1038/ncomms2921

[12] Pommier, Y., Leo, E., Zhang, H. and Marchand, C. (2010) DNA Topoisomerases and Their Poisoning by Anticancer and Antibacterial Drugs. Chemistry \& Biology, 17, 421-433. https://doi.org/10.1016/j.chembiol.2010.04.012

[13] MInotti, G., et al. (2008) Anthracyclines. In: Offermanns, S. and Rosenthal, W., Eds., Encyclopedia of Molecular Pharmacology, Vol. 1, 2nd Edition, Springer, Berlin.

[14] Momparler, R.L., Karon, M., Siegel, S.E. and Avila, F. (1976) Effect of Adriamycin on DNA, RNA, and Protein Synthesis in Cell-Free Systems and Intact Cells. Cancer Research, 36, 2891-2895.

[15] Ha, J., Hwang, D., Yu, J., Park, D. and Ryu, H. (2011) Onset of Manic Episode during Chemotherapy with 5-Fluorouracil. Psychiatry Investigation, 8, 71-73.

[16] Longley, B., Harkin, P. and Johnston, G. (2003) 5-Fluorouracil: Mechanisms of Action and Clinical Strategies. Nature Reviews Cancer, 3, 330-338.

https://doi.org/10.1038/nrc1074

[17] Bankston, R. and Kass, R.S. (2010) Molecular Determinants of Local Anesthetic Action of Beta-Blocking Drugs: Implications for Therapeutic Management of Long QT Syndrome Variant 3. Journal of Molecular and Cellular Cardiology, 48, 246-253. https://doi.org/10.1016/j.yjmcc.2009.05.012

[18] Wang, W., Mistry, M., Kahlig, M., Kearney, A., Xiang, J. and George, L. (2010) Propranolol Blocks Cardiac and Neuronal Voltage-Gated Sodium Channels. Fron- 
tiers in Pharmacology, 1, 144. https://doi.org/10.3389/fphar.2010.00144

[19] Desaphy, J.F., Pierno, S., De Luca, A., Didonna, P. and Camerino, D.C. (2003) Different Ability of Clenbuterol and Salbutamol to Block Sodium Channels Predicts Their Therapeutic Use in Muscle Excitability Disorders. Molecular Pharmacology, 63, 659-670. https://doi.org/10.1124/mol.63.3.659

[20] Thorn, C.F, Oshiro, C., Marsh, S., Boussard, T.H., McLeod, H., Klein, T.E., Russ, B. and Altman, R.B. (2011) Doxorubicin Pathways: Pharmacodynamics and Adverse Effects. Pharmacogenet Genomics, 21, 440-446. https://doi.org/10.1097/FPC.0b013e32833ffb56

[21] van Kuilenburg, A.B.P., Häusler, P., Schalhorn, A., Tanck, M.W.T., Proost, J.H., Terborg, C. and Maring, J.G. (2012) Evaluation of 5-Fluorouracil Pharmacokinetics in Cancer Patients with a c.1905+1G>A Mutation in DPYD by Means of a Bayesian Limited Sampling Strategy. Clinical Pharmacokinetics, 51, 163-174. https://doi.org/10.1007/BF03257473

[22] Etienne, M.C., Milano, G., Renée, N., Lagrange, J.L., Dassonville, O., Thyss, A. and Demard, F. (1195) Population Study of Dihydropyrimidine Dehydrogenase in Cancer Patients. Bulletin Du Cancer, 82, 705-710.

[23] Borràs, E., Doto, E., Arcusa, A., Gamundi, M.J., Herna, I., Dias, M. and Carballo, M. (2012) High-Resolution Melting Analysis of the Common c.1905+1G>A Mutation Causing Dihydropyrimidine Dehydrogenase Deficiency and Lethal 5-Fluorouracil Toxicity. Frontiers in Genetics, 3, 312-312.

[24] Kuilenburg, A.B., Muller, E.W., Haasjes, J., Meinsma, R., Zoetekouw, L., Waterham, H.R. and Gennip, A.H. (2001) Lethal Outcome of a Patient with a Complete Dihydropyrimidine Dehydrogenase (DPD) Deficiency after Administration of 5-Fluorouracil: Frequency of the Common IVS14 + 1G > A Mutation Causing DPD Deficiency. Clinical Cancer Research: An Official Journal of the American Association for Cancer Research, 7, 1149-1153

[25] Latchman, J., Guastella, A.M. and Tofthagen, C. (2014) 5-Fluorouracil Toxicity and Dihydropyrimidine Dehydrogenase Enzyme: Implications for Practice. Clinical Journal of Oncology Nursing, 18, 581-585. https://doi.org/10.1188/14.CJON.581-585

[26] Pantziarka, P., Bouche, G., Sukhatme, V., Meheus, L., Rooman, I. and Sukhatme, V.P. (2016) Repurposing Drugs in Oncology (ReDO)-Propranolol as an Anti-Cancer Agent. Ecancermedicalscience, 10, 680.

[27] Rastegar, H., Ahmadi, H., Anjarani, S., et al. (2013) The Role of Milk Thistle Extract in Breast Carcinoma Cell Line (MCF-7) Apoptosis with Doksorubisin. Acta Medica Iranica, 51, 591-598.

[28] Zoli, W., Ulivi, P., Tesei, A., Fabbri, F., Rosetti, M., Maltoni, R., Giunchi, D.C., Luca, L., Brigliadori, G., Vannini, I. and Amadori, D. (2005) Addition of 5-Fluorouracil to Doxorubicin-Paclitaxel Sequence Increases Caspase-Dependent Apoptosis in Breast Cancer Cell Lines. Breast Cancer Research, 7, R681-R689. https://doi.org/10.1186/bcr1274

[29] Kugawa, F., Ueno, A., Kawasakı, M. and Aokı, M. (2004) Evaluation of Cell Death Caused by CDF (Cyclophosphamide, Doxorubicin, 5-Fluorouracil) Multi-Drug Administration in the Human Breast Cancer Cell Line MCF-7. Biological and Pharmaceutical Bulletin, 27, 392-398. https://doi.org/10.1248/bpb.27.392

[30] Pasquier, E., Ciccolini, J., Carre, M., Giacometti, S., Fanciullino, R., Pouchy, C., Montero, M.P., Serdjebi, C., Kavallaris, M. and André, N. (2011) Propranolol Potentiates the Anti-Angiogenic Effects and Antitumor Efficacy of Chemotherapy 
Agents: Implication in Breast Cancer Treatment. Oncotarget, 2, 797-809. https://doi.org/10.18632/oncotarget.343

[31] Thaker, P.H., Han, L.Y., Kamat, A.A., Arevalo, J.M., Takahashi, R., Lu, C., Jennings, N.B., Armaiz-Pena, G., Bankson, J.A., Ravoori, M., Merritt, W.M., Lin, Y.G., Mangala, L.S., Kim, T.J., Coleman, R.L., Landen, C.N., et al. (2006) Chronic Stress Promotes Tumor Growth and Angiogenesis in a Mouse Model of Ovarian Carcinoma. Nature Medicine, 12, 939-944. https://doi.org/10.1038/nm1447

[32] Sloan, E.K., Priceman, S.J., Cox, B.F., Yu, S., Pimentel, M.A., Tangkanangnukul, V., Arevalo, J.M., Morizono, K., Karanikolas, B.D., Wu, L., Sood, A.K. and Cole, S.W. (2010) The Sympathetic Nervous System Induces a Metastatic Switch in Primary Breast Cancer. Cancer Research, 70, 7042-7052. https://doi.org/10.1158/0008-5472.CAN-10-0522

[33] Schuller, H.M. (2010) Beta-Adrenergic Signaling, a Novel Target for Cancer Therapy? Oncotarge, 1, 466-469.

[34] Soule, H.D., Vazquez, J., Long, A., Albert, S. and Brennan, M. (1973) A Human Cell Line from a Pleural Effusion Derived from a Breast Carcinoma. Journal of the National Cancer Institute, 51, 1409-1416. https://doi.org/10.1093/jnci/51.5.1409

[35] Ashburn, T.T. and Thor, K.B. (2004) Drug Repositioning: Identifying and Developing New Uses for Existing Drugs. Nature Reviews Drug Discovery, 3, 673-683. https://doi.org/10.1038/nrd1468

[36] O’Connor, K.A. and Roth, B.L. (2005) Finding New Tricks for Old Drugs: An Efficient Route for Public-Sector Drug Discovery. Nature Reviews Drug Discovery, 4 1005-1014. https://doi.org/10.1038/nrd1900

[37] Martin, H., Smith, L. and Tomlinson, D. (2014) Multidrug-Resistant Breast Cancer: Current Perspectives. Breast Cancer. Targets and Therapy, 6, 1-13. 